\title{
Possible Role of Garlic Oil and Parsley Extract in Ameliorating Radiation-Induced Bone Loss in Female Rats
}

\author{
L. Ramadan, W. El-Sabbagh and S. Kenawy ${ }^{*}$ \\ Drug Radiation Research Dept., National Center for Radiation \\ Research and Tecchnology (NCRRT), P. O. Box; 29 Nasr City, \\ Egypt and *Pharmacology and Toxicology Dept., Faculty of \\ Pharmacy, Cairo University, Egypt.
}

\begin{abstract}
TO INVESTIGATE the possible protective effect of garlic oil and parsley extract against bone loss resulted in female virgin rats exposed to fractionated doses of $\gamma$-radiation (1Gy 3 times weekly for 5 weeks). Urinary calcium (uCa), calcium to creatinine ratio $(\mathrm{Ca} / \mathrm{Cr})$, hydroxyproline and serum phosphorus were measured as bone resorption biomarkers, while serum osteocalcine (OST) and serum alkaline phosphatase (ALP) were measured as bone formation biomarkers. Furthermore, nitric oxide (NO) which represents the balance in bone remodeling was measured. Malondiadehyde level (MDA) as well as superoxide dismutase activity (SOD) was measured as oxidative stress biomarkers.

Female irradiated rats in the present study had significant increases in both bone resorption and bone formation biomarkers after 6 weeks from the last exposure to $\gamma$-radiation. Irradiated rats also had significant decreases in plasma NO indicating imbalance in bone remodeling as well as significant increase in oxidative stress biomarkers. Daily treatment with garlic oil extracted in olive oil improved all measured parameters except OST level, while the vehicle used for garlic oil (extra virgin olive oil) significantly decreased bone resorption biomarkers. Parsley extract induced normalization to all bone resorption and formation parameters measured in irradiated rats. Daily administration of garlic oil and parsley extract protected the bone from degeneration induced by exposure to fractionated doses of gamma radiation. Keywords: $\gamma$-irradiation, garlic oil, parsley extract.
\end{abstract}

Bone is often subjected to high doses of radiation in an effort to control cancer; so irradiation is one of the factors that exert a negative effect on osteogenesis. In clinical studies, atrophy and high susceptibility to fractures of the bone in radiation exposure field have been reported by Ergun and Howland (1980). 
Jenkins et al. (1995) recorded hip fractures complications in patients who received chemo-radiotherapy for carcinoma of the vulva or anus. In young mice, haematological and skeletal changes have been observed after long term continuous external whole body irradiations; this was explained by alteration in bone remodelling which resulted from radiation injury to osteoclast precursors in the haematopoietic compartment as shown by Anderson et al. (1997). On the other hand, Matsumura et al. (1998) demonstrated that DNA content and total calcium content in osteoblast cell cultures were decreased by irradiation, leading to decreases in whole matrix calcification.

Gamma radiation affected sex hormones which play a role in bone metabolism. It was shown by Lee and Yoon (2005) that gamma radiation induced apoptotic and inflammatory degeneration of ovarian follicles in mice. The naturally occurring antioxidants are part of the natural biochemical defence system that evolved to protect cells against free radicals and reactive oxygen species arising from normal metabolic processes. A large number of plants containing antioxidant phytochemicals were reported to be radio protective in various model systems. The aim of the present study is to investigate the possible protective effects of certain natural products against bone loss that normally results in female rats after exposure to fractionated doses of $\gamma$ radiation, and the possible role played by antioxidants in protection from the damaging effect of radiation on bone.

\section{Material and Methods}

\section{Animals}

Female albino virgin rats, matched for age and weight (180-200 g), were obtained from the animal house of the Research Institute of Ophthalmology, Giza, Egypt. Animals were kept at room temperature and allowed free access to water and food (standard pellet diet). The study was carried out according to the guidelines of the ethical committee in Faculty of Pharmacy, Cairo University.

\section{Drugs}

Garlic oil extracted and suspended in pure extra virgin olive oil, (Nature's way products Inc., USA), and Parsley leaves extract (Nature Answer Inc., USA). Oestradiol benzoate (Misr Company for pharmaceutical Industries, Egypt) used as reference standard drug.

Egypt. J. Rad. Sci. Applic., Vol. 24, No. 1 (2011) 


\section{Irradiation}

Whole body $\gamma$-irradiation was carried out using the facilities provided by NCRRT. Cesium-137 irradiation unit (Gamma cell-40) produced by the Atomic Energy of Canada Limited was used at a dose rate of $0.84 \mathrm{~Gy} / \mathrm{min}$ at the time of experiment. A pilot test was carried out to estimate the degree of bone loss in rats exposed to fractionated doses of $\gamma$-irradiation (1Gy 3 times a week ( 2 days gap) for 5 weeks equivalent to $15 \mathrm{~Gy}$ ). Urine samples were collected 4, 8, 11 and 15 weeks after the first dose of irradiation for measuring $\mathrm{Ca}$ and hydroxyproline levels to evaluate rate of bone resorption.

\section{Experimental design}

A total of 36 rats were divided into 6 groups each of 6 rats as follows: Rats in the $1^{\text {st }}$ group were non-irradiated and served as normal group, while in the $2^{\text {nd }}$ group rats were exposed to 15 Gy $\gamma$-radiation (1Gy 3 times weekly for 5 weeks). The $3^{\text {rd }}$ group consisted of irradiated rats treated daily with oral doses of garlic oil $(100 \mathrm{mg} / \mathrm{kg})$ in olive oil according to Gupta (1996) for 5 weeks. Irradiated rats in the $4^{\text {th }}$ group were treated with extra virgin olive oil calculated to be equivalent to the amount used as a vehicle with garlic oil ( $2 \mathrm{~g} / \mathrm{kg}$ for 5 weeks/ orally). In the $5^{\text {th }}$ group, irradiated rats were treated as in the $3^{\text {rd }}$ comprised group but using parsley extract instead of garlic oil. The $6^{\text {th }}$ group irradiated rats injected s.c. daily for 5 weeks with oestradiol benzoate $(30 \mu \mathrm{g} / \mathrm{kg})$ according to the study of Shen et al. (1993).

\section{Laboratory measurements}

Urinary calcium $(\mathrm{Ca})$, urinary calcium to creatinine ratio $(\mathrm{Ca} / \mathrm{Cr})$, urinary hydroxyproline and serum phosphorus were measured as bone resorption biomarkers. Calcium, creatinine, phosphorus and hydroxyproline were measured according to Gindler and King (1972), Schirmeister et al. (1964), ElMerzabani et al. (1977) and Woessner (1961). Serum osteocalcin (OST) and serum alkaline phosphatase (ALP) activity were measured as bone formation biomarkers according to Power and Fottrell (1991) and Belfield and Goldberg (1971). Nitric oxide (NO) was estimated in plasma as it reflects the balance in bone remodeling according to Montgomery and Dymock (1961). Plasma malondialdehyde (MDA) and blood superoxide dismutase activity were measured as oxidative stress biomarkers according to the methods of Yoshioka et al (1979) and Marklund and Marklund (1974), respectively.

Egypt. J. Rad. Sci. Applic., Vol. 24, No. 1 (2011) 


\section{Statistical evaluation}

All values are expressed as means \pm S.E. Data were analyzed using one way ANOVA followed by Tukey-Kramer multiple comparison test. The p value was considered significant at $p<0.05$. Graphpad software instant (version 2) was used to carry out these statistical tests.

\section{Results}

\section{Pilot experiment}

Exposing female rats to $\gamma$-radiation (15 Gy fractionated at three doses a week, each of 1 Gy for 5 weeks) induced a gradual increase in urinary calcium excretion along a period of 15 weeks.
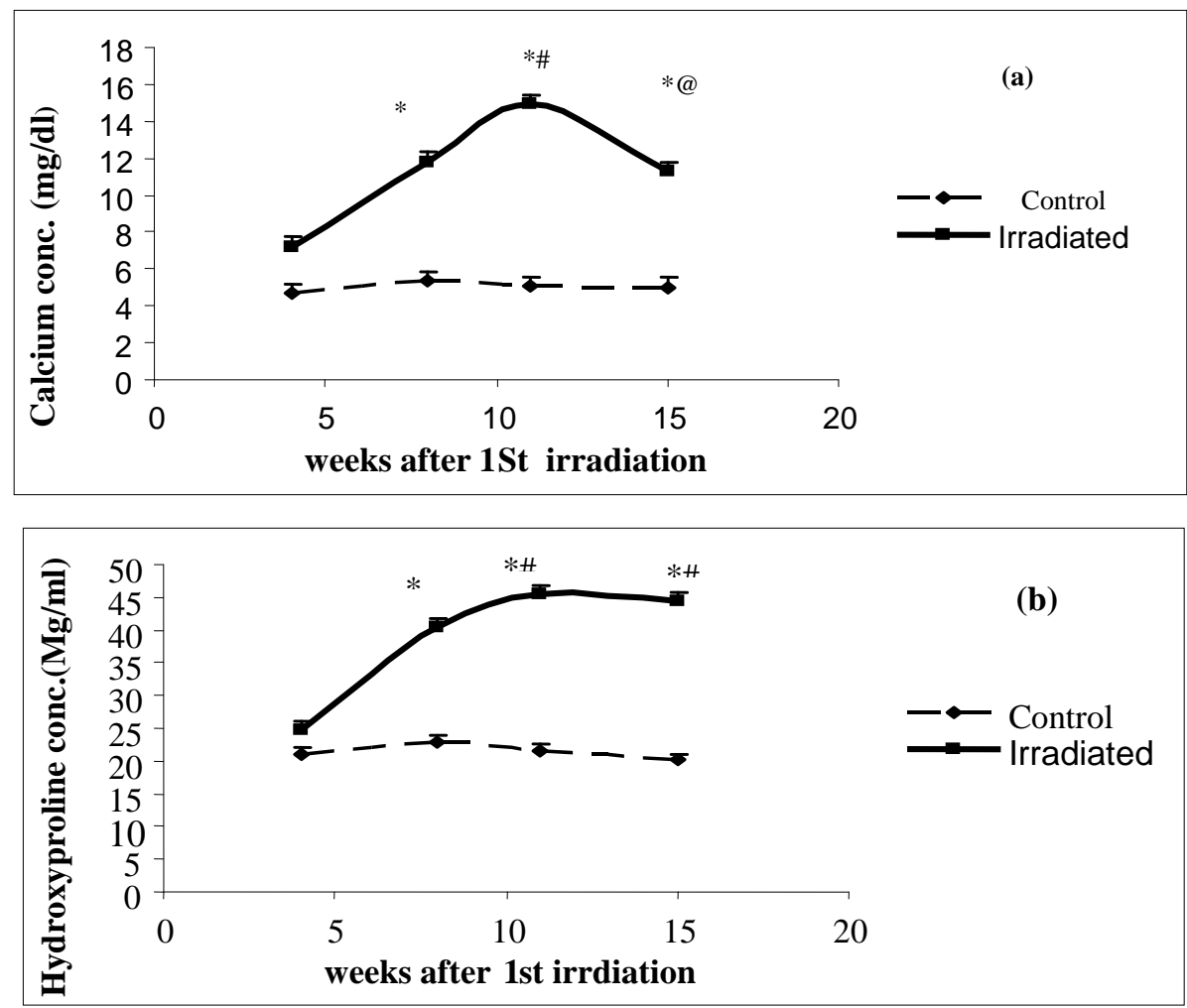

Fig. 1. Changes in urinary calcium conc. (mg/dl) (a) and hydroxyproline conc. $(\mu \mathrm{g} / \mathrm{ml})(\mathrm{b})$ of female irradiated rats $(15 \mathrm{~Gy} ; 1 \mathrm{~Gy} 3$ times a week for 5 weeks) after 4, 8, 11 and 15 weeks from the first dose of irradiation.

*. significantly different from value after 4 weeks at $\mathrm{P} \leq 0.05$.

\#. significantly different from

value after 8 weeks at $\mathrm{P} \leq 0.05$.

@. significantly different from value after 11 weeks at $\mathrm{P} \leq 0.05$.

Egypt. J. Rad. Sci. Applic., Vol. 24, No. 1 (2011) 
The $1^{\text {st }}$ significant increase in urinary calcium was detected after 8 weeks from the $1^{\text {st }}$ exposure to $\gamma$-radiation. However, the peak of calcium excretion was detected at the $11^{\text {th }}$ week (Fig. 1).

On the other hand, at the $8^{\text {th }}$ week, the urinary hydroxyproline level increased significantly by $63.1 \%$ compared with that in the $4^{\text {th }}$ week. Furthermore at the $11^{\text {th }}$ week, excretion of hydroxyproline significantly increased reaching the maximum; this level remained nearly constant till the $15^{\text {th }}$ week (Fig. 1).

\section{Urinary $\mathrm{Ca}$ and $\mathrm{Ca} / \mathrm{Cr}$ ratio}

Fig. 2. Showed that $\gamma$-rays induced a significant increase in urinary calcium excretion by $199.44 \%$ compared to control non irradiated rats. Administration of garlic oil, suspended in extra virgin olive oil, to irradiated rats showed a significant decrease in urinary calcium level by $70.1 \%$.

On the other hand, daily administration of extra virgin olive oil alone to irradiated rats inhibited the increase in urinary calcium level induced by $\gamma$-rays only by $48.3 \%$.

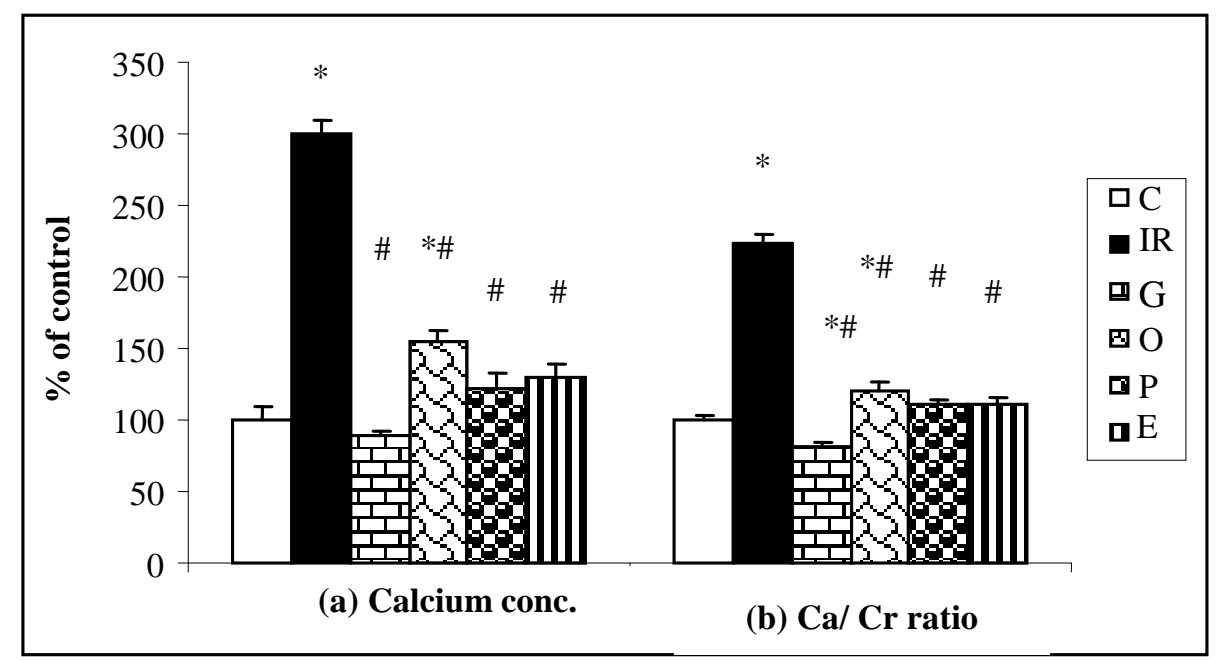

Fig. 2. Effect of garlic oil (100 mg/kg), extra virgin olive oil ( $2 \mathrm{~g} / \mathrm{kg})$, parsley extract (100 $\mathrm{mg} / \mathrm{kg})$ and oestradiol benzoate $(30 \mu \mathrm{g} / \mathrm{kg})$ on calcium conc. ( $\mathrm{mg} / \mathrm{dl})(\mathrm{a})$ and calcium to creatinine ratio $(b)$ in urine of female irradiated rats.

Legends as in Fig. 1. All data taken at 11 weeks post first irradiation, $\mathrm{C}=$ control normal group, $\mathrm{IR}=$ irradiated group, $\mathrm{G}=$ garlic oil treated group, $\mathrm{O}=$ olive oil treated group, $\mathrm{P}=$ parsley treated group, $\mathrm{E}=$ oestradiol treated group. 
Parsley extract also significantly decreased the calcium level in urine of irradiated rats by $59.5 \%$, while a significant decrease in urinary calcium level by $56.6 \%$ in irradiated rats was observed after daily injections with oestradiol benzoate. The administration of garlic oil extracted in olive oil, extra virgin olive oil, parsley extract and oestradiol benzoate to irradiated rats significantly decreased the $\mathrm{Ca} / \mathrm{Cr}$ ratio by $63.9 \%, 46.2 \%, 50.6 \%$ and $50.2 \%$ respectively (Fig. 2).

\section{Urinary hydroxyproline and serum phosphorus levels}

Irradiation induced a significant increase in urinary hydroxyproline level by $147 \%$. Garlic oil extracted in olive oil, extra virgin olive oil, parsley extract and oestradiol benzoate significantly decreased the urinary hydroxyproline level in irradiated rats by $44.6 \%, 39.04 \%, 50.7 \%$ and $53.4 \%$ respectively (Fig. 3). Fig. 3. demonstrated that $\gamma$-irradiation significantly increased serum inorganic phosphorus level by $62.7 \%$. Both garlic oil and parsley extract normalized the serum inorganic phosphorus level in irradiated rats. Extra virgin olive oil and oestradiol benzoate significantly decreased serum phosphorus level by $26.5 \%$ and $22.5 \%$ respectively in irradiated rats.

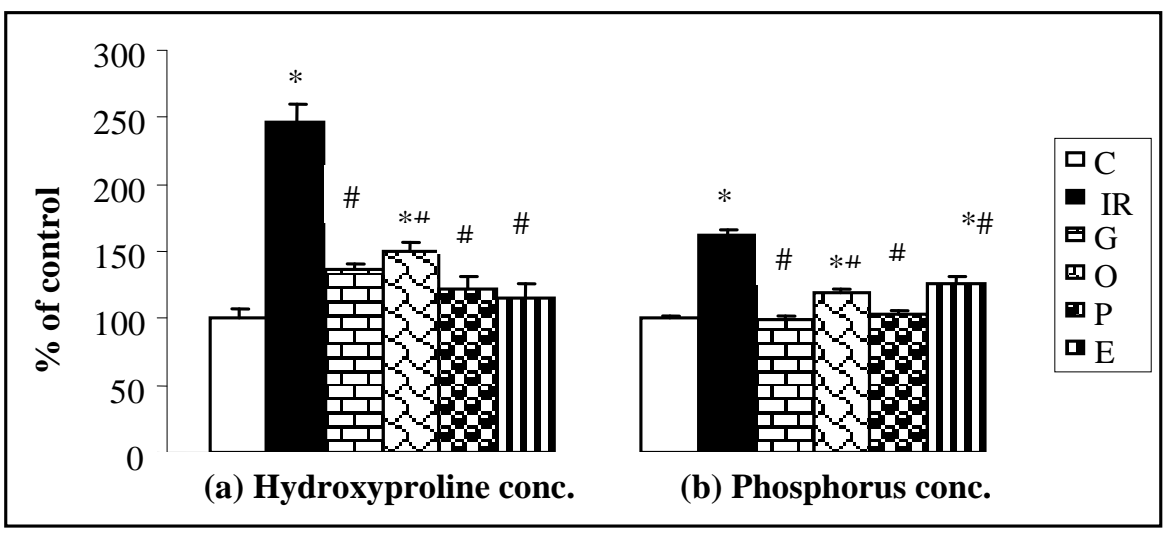

Fig. 3. Effect of garlic oil $(100 \mathrm{mg} / \mathrm{kg})$, extra virgin olive oil $(2 \mathrm{~g} / \mathrm{kg})$, parsley extract $(100 \mathrm{mg} / \mathrm{kg})$ and oestradiol benzoate $(30 \mu \mathrm{g} / \mathrm{kg})$ on urinary hydroxyproline conc. $(\mu \mathrm{g} / \mathrm{ml})(a)$ and serum phosphorus conc. $(\mathrm{mg} / \mathrm{dl})(b)$ of female irradiated.

Legends as in Fig. 2.

Serum OST level, serum ALP activity and plasma NO

After 11 weeks from the $1^{\text {st }}$ exposure to $\gamma$-radiation, serum osteocalcin was significantly increased by $22.9 \%$ when compared with control values. Egypt. J. Rad. Sci. Applic., Vol. 24, No. 1 (2011) 
Parsley extract and oestradiol benzoate significantly decreased serum osteocalcin level in irradiated rats by $31.9 \%$ and $22.2 \%$ respectively (Fig. 4).

Fig. 4. Showed an increase in ALP activity of irradiated rats by $78.5 \%$ compared with control rats. Daily administration of garlic oil normalized the activity of serum ALP.

Extra virgin olive oil, parsley extract and oestradiol benzoate induced a significant decrease in ALP activity of irradiated rats by $23.15 \%, 33.04 \%$ and $35.4 \%$ respectively. Fig. 4. showed that female irradiated rats showed a significant decrease by $59.4 \%$ in plasma nitric oxide level. However, daily administration of garlic oil, extra virgin olive oil, parsley extract and oestradiol benzoate induced significant increases in NO levels by $205.4 \%, 116.4 \%$, $191.42 \%$ and $147.8 \%$ respectively.

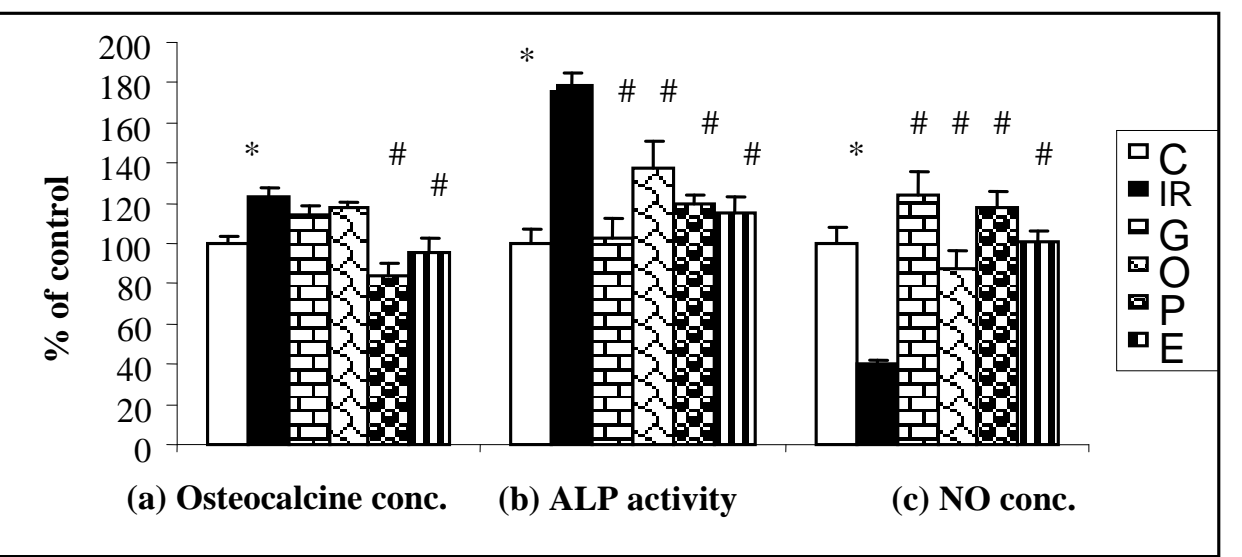

Fig. 4. Effect of garlic oil $(100 \mathrm{mg} / \mathrm{kg})$, extra virgin olive oil $(2 \mathrm{~g} / \mathrm{kg})$, parsley extract $(100 \mathrm{mg} / \mathrm{kg})$ and oestradiol benzoate $(30 \mu \mathrm{g} / \mathrm{kg})$ on serum osteocalcine conc. $(\mathrm{ng} / \mathrm{dl})(\mathrm{a})$, serum alkaline phosphatase activity (IU/l) (b) and plasma nitric oxide conc. $(\mu \mathrm{mol} / \mathrm{l})(\mathrm{c})$ of female irradiated rats.

The legends as in Fig. 3.

\section{Plasma MDA level and blood SOD activity}

Exposure to fractionated doses of $\gamma$-irradiation (three doses a week each of 1 Gy for 5 weeks) induced a significant increase in MDA level by $85.8 \%$.

Data showed that garlic oil, extra virgin olive oil, parsley extract and oestradiol benzoate exerted a significant decrease by $44.1 \%, 22.3 \%, 28.1 \%$ and $40.4 \%$ respectively in MDA levels of irradiated rats (Fig. 5).

Egypt. J. Rad. Sci. Applic., Vol. 24, No. 1 (2011) 
Results showed that 6 weeks after exposure to 15 Gy a significant decrease in blood SOD activity by $49.2 \%$ was detected in irradiated rats. Administration of garlic oil extracted in olive oil induced a significant increase in SOD levels in irradiated rats by $81.4 \%$, whereas extra virgin olive oil could not induce a significant increase in blood SOD level. Moreover, parsley extract and oestradiol benzoate induced significant increase in SOD levels in irradiated rats by $60 \%$ and $82.8 \%$ respectively (Fig. 5 ).

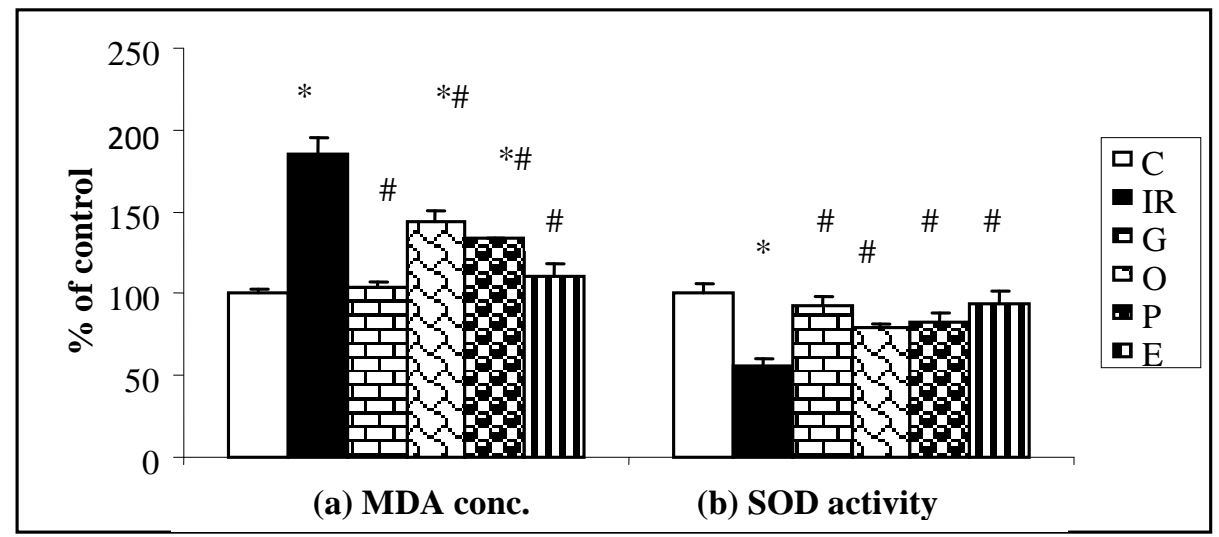

Fig. 5. Effect of garlic oil $(100 \mathrm{mg} / \mathrm{kg})$, extra virgin olive oil $(2 \mathrm{~g} / \mathrm{kg})$, parsley extract $(100 \mathrm{mg} / \mathrm{kg})$ and oestradiol benzoate $(30 \mu \mathrm{g} / \mathrm{kg})$ on plasma MDA conc. $(\mathrm{nmol} / \mathrm{ml})(\mathrm{a})$ and blood SOD activity $(\mathrm{U} / \mathrm{ml})(\mathrm{b})$ in female irradiated rats.

The legends as in Fig. 3.

\section{Discussion}

Irradiated rats showed a significant increase in bone resorption biomarkers $(\mathrm{Ca}, \mathrm{Ca} / \mathrm{Cr}$, hydroxyproline and phosphorus) after 6 weeks from the total exposure to fractionated 15 Gy dose. Present results also showed significant increases in serum OST and ALP levels in irradiated rats indicating high bone turnover rate after exposure to $\gamma$-irradiation. This was in accordance with the study of Chicarelli et al. (2007) who pointed out that irradiation affected the beginning of bone formation as well as acceleration of bone resorption in rats exposed to $\gamma$-radiation. However, several factors may be involved in the pathogenicity of osteoporosis after exposure to fractionated doses of $\gamma$ irradiation; as thyrotoxicosis (Nishiyama et al., 1996) which could be linked to osteoporosis (Lakatos, 2003). Additionally, Girinsky et al. (1994) demonstrated that total body irradiation with a dose of $10 \mathrm{~Gy}$ induced a massive increase in Egypt. J. Rad. Sci. Applic., Vol. 24, No. 1 (2011) 
levels of bone resorbing cytokines in blood accompanied by a dramatic increase in levels of adrenocorticotrophic hormone (ACTH) inducing an increase in serum cortisol that has adverse effects on bone metabolism.

Daily treatment with garlic oil extracted in olive oil in the present experiment showed a possible protection against bone loss in irradiated rats. The significant decrease in $\mathrm{Ca} / \mathrm{Cr}$ ratio as well as normalization of both urinary hydroxyproline and serum phosphorus levels could be linked to the ability of garlic oil in suppression of bone resorption induced by irradiation. Previously mentioned results of the use of garlic oil on irradiated rats revealed its radio protective effects. Singh et al. (1996) has reported the radio protective efficacy of garlic extract against irradiation damage in mice. However, the presence of trace elements such as selenium having antioxidant effects in garlic plant (Ip and Lisk, 1995) may explain one of radio protective properties of garlic plant. Our results showed that although extra virgin olive oil induced significant decrease in urinary $\mathrm{Ca} / \mathrm{Cr}$ ratio, hydroxyproline and serum phosphorus level in irradiated rats, their levels were still significantly more than control values. On the other hand, although extra virgin olive oil significantly decreased serum ALP, it did not affect serum OST level. It can be suggested that the selected dose of extra virgin olive oil $(2 \mathrm{~g} / \mathrm{kg})$ in the current study was not sufficient for complete protection from damage in bone of irradiated rats.

Parsley is rich with apigenin flavonoid which has a radio protective effect (Rithidech et al., 2005) current results showed that daily administration of parsley extract induced a significant decrease in $\mathrm{Ca} / \mathrm{Cr}$ ratio as well as hydroxyproline level in urine of female irradiated rats. In the current study, oestradiol benzoate could maintain the normal bone turnover rate in irradiated rats, this may be related to inhibition of both production and activity of bone resorbing cytokines by oestrogen (Manolagas and Jilka, 1995). Our results showed that exposure of rats to 15 Gy $\gamma$-rays (1Gy 3 times a week for 5 weeks) significantly decreased plasma NO level when compared with non irradiated rats. This may be explained by the study of Tishkin et al. (2007) who showed that whole body gamma irradiation induced endothelium dysfunction by suppressing calcium-activated potassium channels in rats which control the driving force for $\mathrm{Ca} 2+$ entry and therefore $\mathrm{Ca} 2+$ dependent $\mathrm{NO}$ synthesis in endothelial cells. 
Garlic oil resulted in normalization of plasma NO level of irradiated rats. Morihara et al. (2002) demonstrated that aged garlic extract increased production of plasma NO by 30-40\%. Extra virgin olive oil showed a significant increase in plasma $\mathrm{NO}$ value compared with that in non-treated group. The capability of virgin olive oil in modulating endothelial activity may be responsible for the increase in NO production by olive oil (Perona et al., 2006). Daily administration of parsley extract induced normalization of plasma NO level of irradiated rats. This could be attributed to the presence of genistein in parsley, depending on results mentioned by Altavilla et al. (2004) who demonstrated that genistein flavonoid increased plasma NO breakdown products, reduced endothelin-1 levels and improved endothelial dependent vasodilatation. Moreover, oestradiol benzoate maintained the normal level of plasma NO in irradiated rats. 17- $\beta$ oestradiol could modulate vascular function by rapid release of NO and up-regulation of eNOS through mitogen-activated protein (MAP) kinase-dependent mechanisms (Chen et al., 1999).

In this study, a significant increase in plasma MDA level as well as a significant decrease in SOD activity was observed in irradiated rats. It has been suggested that irradiation caused a marked change in the plasma total antioxidant capacity and large increase in oxidative stress (Chevion et al., 1999). Rats supplemented with garlic oil in our study exhibited a significant decrease in MDA level and normalization of SOD activity. However, it has been reported before that garlic oil enhanced antioxidant and detoxifying enzyme systems (Saravanan and Prakash, 2004). Extra virgin olive oil showed a significant decrease in plasma MDA level; this was in accordance with Bogani et al. (2007) who reported that extra virgin olive oil could significantly increase serum antioxidant capacity. Parsley extract induced a significant decrease in MDA level and a significant increase in SOD activity in irradiated rats. It has been found by Nielsen et al. (1999) that supplementation of parsley rich with apigenin flavonoid for 2 weeks was sufficient to induce a significant increase in erythrocyte glutathione reductase and SOD activities in plasma.

Oestradiol benzoate induced a significant decrease in MDA level of irradiated rats as well as a significant increase in SOD activity. Ruiz-Larrea $e t$ al. (1994) suggested that the antioxidant properties of oestrogens are due to the presence of phenolic group in their steroid structure.

Egypt. J. Rad. Sci. Applic., Vol. 24, No. 1 (2011) 
The beneficial effects of garlic oil and parsley extract against irradiation induced bone loss in female rats are demonstrated in the present findings. However, further studies are needed to investigate the factors participating in the development of osteoporosis after long exposure to $\gamma$-radiation.

\section{References}

Altavilla, D., Crisafulli, A., Marini, H., Esposito, M., D’Anna, R., Corrado, F., Bitto, A. and Squadrito, F. (2004) Cardiovascular effects of the phytoestrogen genistin. Curr. Med. Chem. Cardiovasc. Hematol. Agents, 2, 179.

Anderson, F. H., Francis, R. M., Bishop, J. C. and Rawlings, D. J. (1997) Effect of intermittent cyclical disodium etidronate therapy on bone mineral density in men with vertebral fractures. Age Ageing, 26, 359.

Belfield, A. and Goldberg, D. M. (1971) Revised assay for serum phenyl phosphatase activity using 4-amino-antipyrine. Enzyme, 12, 561.

Bogani, P., Galli, C., Villa, M. and Visioli, F. (2007) Postprandial anti-inflammatory and antioxidant effects of extra virgin olive oil. Atherosclerosis, 190, 181.

Chen, Z., Yuhanna, I. S., Galcheva-Gargova, Z., Karas, R. H., Mendelsohn, M. E., Shaul, P. W. (1999) Estrogen receptor alpha mediates the nongenomic activation of endothelial nitric oxide synthase by estrogen. J. Clin. Invest., 103, 401.

Chevion, S., Or, R. and Berry, E. M. (1999) The antioxidant status of patients subjected to total body irradiation. Biochem. Mol. Biol. Int., 47, 1019.

Chicarelli, M., Ramos, F. M., Manzi, F. R., Novaes, P. D., Boscolo, F. N. and Almeida, S. M. (2007) Effect of gamma rays on the bone repair process in rats with estrogen deficiency. Pesqui. Odontol. Bras, 21, 75.

El-Merzabani, M. M., Anwer-El-Aaser, A. and Zakhary, N. I. (1977) A new method for determination of inorganic phosphorus in serum without deproteinization. J. Clin. Chem. Clin. Biochem., 15, 715.

Ergun, H. and Howland, W. J. (1980) Postradiation atrophy of mature bone. Crit. Rev. Diagn. Imaging, 12, 225.

Gindler, M. E. and King, J. D. (1972) Rapid Colorometric determination of Calcium in biological fluids with methyl thymol blue. Am. J. Clin. Path., 58, 376.

Girinsky, T. A., Pallardy, M., Comoy, E., Benassi, T., Roger, R., Ganem, G., Cosset, J. M., Socie, G. and Magdelenat, H. (1994) Peripheral blood corticotropin-releasing factor, adrenocorticotropic hormone and cytokine (interleukin beta, interleukin 6, tumor necrosis factor alpha) levels after highand low-dose total-body irradiation in humans. Radiat. Res., 139, 360.

Gupta, N. K. (1996) Modification of radiation-induced changes in murine hepatic lipid profile by garlic (Allium Sativum Linn.) unsaturated oils. Indian J. EXP. Biol., 34, 851. 
Ip, C. and Lisk, D. J. (1995) Efficacy of cancer prevention by high-selenium garlic is primarily dependent on the action of selenium. Carcinogenesis, 16, 2649.

Jenkins, P. J., Montefiore, D. J. and Arnott, S. J. (1995) Hip complications following chemoradiotherapy. Clin. Oncol., 7, 123.

Lakatos, P. (2003) Thyroid hormones: beneficial or deleterious for bone? Calcif. Tissue Int., 73, 205.

Lee, C. J. and Yoon, Y. D. (2005) Gamma-radiation-induced follicular degeneration in the prepubertal mouse ovary. Mutat. Res., 578, 247.

Manolagas, S. C. and Jilka, R. L. (1995) Bone marrow, cytokines, and bone remodeling. Emerging insights into the pathophysiology of osteoporosis. $N$. Engl. J. Med., 332, 305.

Marklund, S. and Marklund, G. (1974) Involvement of the superoxide anion radical in the autoxidation of pyrogallol and a convenient assay for superoxide dismutase. Eur. J. Biochem., 47, 469.

Matsumura, S., Hiranuma, H., Deguchi, A., Maeda, T., Jikko, A. and Fuchihata, H. (1998) Changes in phenotypic expression of osteoblasts after Xirradiation. J. Radiat. Res., 149, 463.

Montgomery, H. A. C. and Dymock, J. F. (1961) The determination of nitrite in water. Analyst, 86, 414.

Morihara, N., Sumioka, I., Moriguchi, T., Uda, N. and Kyo, E. (2002) Aged garlic extract enhances production of nitric oxide. Life Sci., 71, 509.

Nielsen, S. E., Young, J. F., Daneshvar, B., Lauridsen, S. T., Knuthsen, P., Sandström, B. and Dragsted, L. O. (1999) Effect of parsley (Petroselinum crispum) intake on urinary apigenin excretion, blood antioxidant enzymes and biomarkers for oxidative stress in human subjects. Br. J. Nutr., 81, 447.

Nishiyama, K., Kozuka, T., Higashihara, T., Miyauchi, K. and Okagawa, K. (1996) Acute radiation thyroiditis. Int J Radiat Oncol Biol Phys, 36, 1221.

Perona, J. S., Cabello-Moruno, R. and Ruiz-Gutierrez, V. (2006) The role of virgin olive oil components in the modulation of endothelial function. J. Nutr. Biochem., 17, 429.

Power, M. J. and Fottrell, P. F. (1991) Osteocalcin: diagnostic methods and clinical applications. Crit. Rev. Clin. Lab. Sci., 28, 287.

Rithidech, K. N., Tungjai, M. and Whorton, E. B. (2005) Protective effect of apigenin on radiation-induced chromosomal damage in human lymphocytes. Mutat. Res., 585, 96.

Ruiz-Larrea, M. B., Leal, A. M., Liza, M., Lacort, M. and de Groot, H. (1994) Antioxidant effects of estradiol and 2-hydroxyestradiol on iron-induced lipid peroxidation of rat liver microsomes. Steroids, 59, 383.

Egypt. J. Rad. Sci. Applic., Vol. 24, No. 1 (2011) 
Saravanan, G. and Prakash, J. (2004) Effect of garlic (Allium sativum) on lipid peroxidation in experimental myocardial infarction in rats. $J$. Ethnopharmacol., 94, 155.

Schirmeister, J., Willmann, H., Kiefer, H. and Hallauer, W. (1964) For and against the usefulness of endogenous creatinine clearance in functional kidney diagnosis. Dtsch. Med. Wschr. , 89, 1640.

Shen, V., Dempster, D. W., Birchman, R., Xu, R. and Lindsay, R. (1993) Loss of cancellous bone mass and connectivity in ovariectomized rats can be restored by combined treatment with parathyroid hormone and estradiol. J. Clin. Invest., 91, 2479.

Singh, S. P., Abraham, S. K. and Kesavan, P. C. (1996) Radioprotection of mice following garlic pretreatment. Br. J. Cancer Suppl., 27, S102.

Tishkin, S. M., Rekalov, V. V., Ivanova, I. V., MoreLand, R. S. and Soloviev, A. I. (2007) Ionizing non-fatal whole-body irradiation inhibits $\mathrm{Ca} 2+-$ dependent $\mathrm{K}+$ channels in endothelial cells of rat coronary artery: possible contribution to depression of endothelium-dependent vascular relaxation. Int. J. Radiat. Biol., 83, 161.

Woessner, J. F. (1961) The determination of hydroxyproline in tissue and protein samples containing small portions of this amino acid. Arch. Biochem. Bioph., 93, 440 .

Yoshioka, T., Kawada, K., Shimada, T. and Mori, M. (1979) Lipid peroxidation in maternal and cord blood and protective mechanism against activated-oxygen toxicity in the blood. Am. J. Obstet. Gynecol., 135, 372.

(Received: 03/07/2011;

accepted: 14/08/2011)

Egypt. J. Rad. Sci. Applic., Vol. 24, No. 1 (2011) 


\title{
اللدور المحتمـل لزيت الثوم ومستخلص البقدونس في تعديل

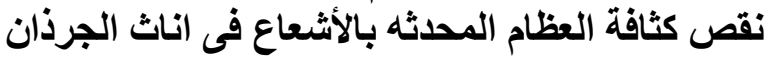

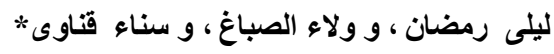

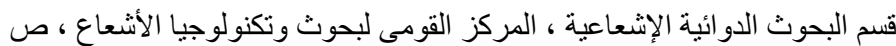

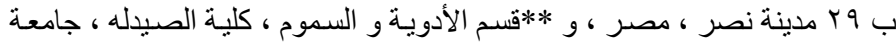

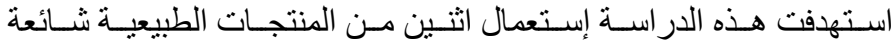

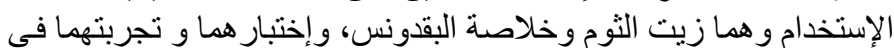

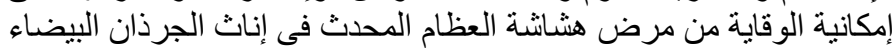

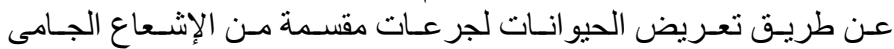

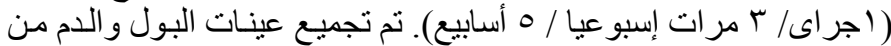

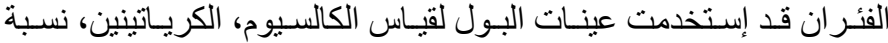

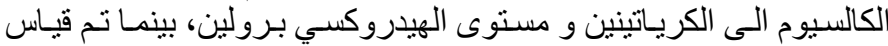

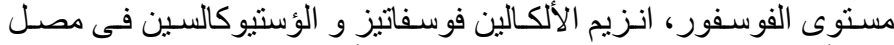

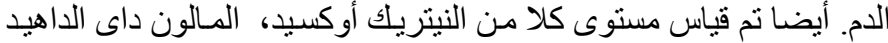

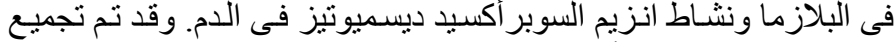

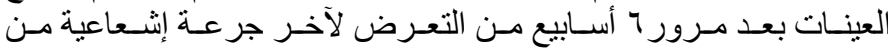

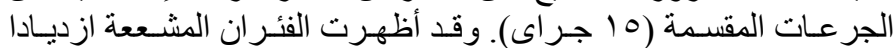

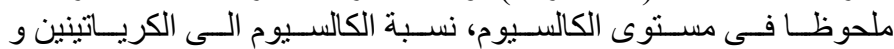

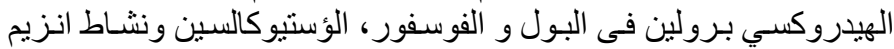

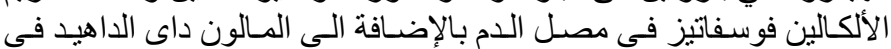

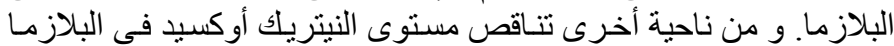

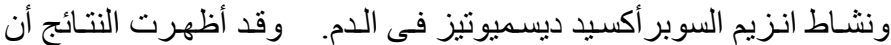

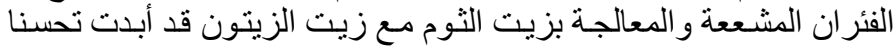

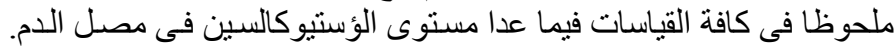

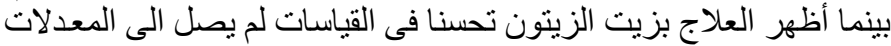

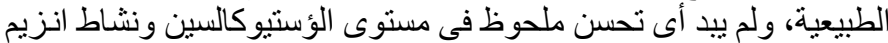

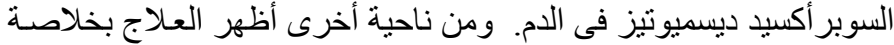

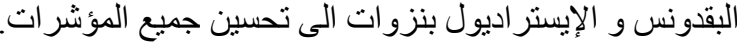

Egypt. J. Rad. Sci. Applic., Vol. 24, No. 1 (2011) 